\title{
Blood flow does not redistribute from respiratory to leg muscles during exercise breathing heliox or oxygen in COPD
}

\author{
Zafeiris Louvaris, ${ }^{1,2}$ Ioannis Vogiatzis, ${ }^{1,2,3}$ Andrea Aliverti, ${ }^{4}$ Helmut Habazettl, ${ }^{5,6}$ Harrieth Wagner, \\ Peter Wagner, ${ }^{7}$ and Spyros Zakynthinos ${ }^{1}$ \\ ${ }^{1}$ First Department of Critical Care Medicine and Pulmonary Services, GP Livanos and M Simou Laboratories, Medical \\ School of Athens University, Evangelismos Hospital, Athens, Greece; ${ }^{2}$ National and Kapodistrian University of Athens, \\ Department of Physical Education and Sports Sciences, Athens, Greece; ${ }^{3}$ University of the West of Scotland, Institute of \\ Clinical Exercise and Health Sciences, Hamilton, United Kingdom; ${ }^{4}$ Dipartimento di Biongegneria, Politecnico di Milano, \\ Milano Italy; ${ }^{5}$ Institute of Physiology, Charite Campus Benjamin Franklin, Berlin, Germany; ${ }^{6}$ Institute of Anesthesiology, \\ German Heart Institute, Berlin, Germany; ${ }^{7}$ Department of Medicine, University of California San Diego, La Jolla, California
}

Submitted 23 January 2014; accepted in final form 30 May 2014

In patients with chronic obstructive pulmonary disease (COPD), one of the proposed mechanisms for improving exercise tolerance, when work of breath-ing is experimentally reduced, is redistribution of blood flow from the respiratory to locomotor muscles. Accordingly, we investigated whether exercise capacity is improved on the basis of blood flow redistribution during exercise while subjects are breathing heliox (designed to primarily reduce the mechanical work of breathing) and during exercise with oxygen supplementation (designed to primarily enhance systemic oxygen delivery but also to reduce mechanical work of breathing). Intercostal, abdominal, and vastus lateralis muscle perfusion were simultaneously measured in 10 patients with COPD (forced expiratory volume in 1 s: $46 \pm 12 \%$ predicted) by near-infrared spectroscopy using indocyanine green dye. Measurements were performed during constant-load exercise at $75 \%$ of peak capacity to exhaustion while subjects breathed room air and, then at the same workload, breathed either normoxic heliox (helium $79 \%$ and oxygen $21 \%$ ) or $100 \%$ oxygen, the latter two in balanced order. Times to exhaustion while breathing heliox and oxygen did not differ $\left(659 \pm 42 \mathrm{~s}\right.$ with heliox and $696 \pm 48 \mathrm{~s}$ with $\left.100 \% \mathrm{O}_{2}\right)$, but both exceeded that on room air $(406 \pm 36 \mathrm{~s}, P<0.001)$. At exhaustion, intercostal and abdominal muscle blood flow during heliox $\left(9.5 \pm 0.6\right.$ and $8.0 \pm 0.7 \mathrm{ml} \cdot \mathrm{min}^{-1} \cdot 100 \mathrm{~g}^{-1}$, respectively) was greater compared with room air $(6.8 \pm 0.5$ and $6.0 \pm 0.5$ $\mathrm{ml} \cdot \mathrm{min}^{-1} \cdot 100 \mathrm{~g} \cdot$, respectively; $\left.P<0.05\right)$, whereas neither intercostal nor abdominal muscle blood flow differed between oxygen and air breathing. Quadriceps muscle blood flow was also greater with heliox compared with room air $\left(30.2 \pm 4.1\right.$ vs. $25.4 \pm 2.9 \mathrm{ml} \cdot \mathrm{min}^{-1} \cdot 100$ $\left.\mathrm{g}^{-1} ; P<0.01\right)$ but did not differ between air and oxygen breathing. Although our findings confirm that reducing the burden on respiration by heliox or oxygen breathing prolongs time to exhaustion (at $75 \%$ of maximal capacity) in patients with COPD, they do not support the hypothesis that redistribution of blood flow from the respiratory to locomotor muscles is the explanation.

Address for reprint requests and other correspondence: S. G. Zakynthinos, 1st Dept. of Critical Care Medicine and Pulmonary Services, Medical School of Athens Univ., Evangelismos Hospital, 45-47str Ipsilandou 10675, Athens, Greece (e-mail: szakynthinos@yahoo.com).
IN PATIENTS WITH CHRONIC OBSTRUCTIVE PULMONARY DISEASE (COPD), exercise capacity is limited by constraints on ventilation and on the mechanisms regulating metabolism and blood supply at the level of the working (respiratory and locomotor) muscles (47).

Reducing the burden on the respiratory muscles during exercise in COPD by breathing pure oxygen or heliox $(2,3,26$, $27,33,46)$ enhances exercise tolerance. However, whether this increase in exercise capacity occurs on the basis of redistribution of blood flow from the respiratory to the locomotor muscles $(1,10,17,18)$ remains largely unknown. Specifically, reports suggest that reducing the work of breathing by heliox $(2,26,46)$ should decrease respiratory muscle blood flow requirement $(16,45)$ and explain increases in leg muscle blood flow (7). However, in our study (46), heliox administration enhanced quadriceps muscle blood flow and oxygen delivery in the absence of reduced intercostal muscle blood flow, thereby disputing the blood flow redistribution hypothesis as a potential mechanism of improvement in leg muscle blood flow. Nevertheless, potential blood flow redistribution from other working respiratory muscle groups, namely the abdominal wall muscles $(21,22,30)$, was not investigated at that time.

The ergogenic effects of oxygen administration on exercise capacity are well documented in patients with $\operatorname{COPD}(3,33)$. Oxygen supplementation primarily enhances arterial oxygen concentration but also lessens the work of breathing $(2,6,31$, 40 ), thereby allowing increased peak work capacity as well as improved peak leg muscle blood flow and oxygen delivery (27). However, the latter study (27) did not examine any potential redistribution of blood flow from the respiratory to the locomotor muscles. By reducing respiratory muscle work load, pure oxygen breathing might decrease the effect of the so-called respiratory muscle metabaroreflex and thus reduce sympathetic vasoconstrictor outflow to the leg muscles during exercise (2).

Accordingly, the purpose of the present study was to investigate whether the well-documented improvement in exercise capacity with heliox or oxygen administration $(2,3,26,27,33$, 46) occurs on the basis of blood flow redistribution from the respiratory to locomotor muscles. To accomplish our goal, we performed simultaneous measurements of quadriceps, intercostal, and abdominal wall muscle blood flow during exercise in room air and while subjects breathed heliox or oxygen. We used both mixtures that are known to enhance exercise capacity in COPD either owing primarily to increased arterial oxygen 
concentration with oxygen supplementation or consequently to reduced work of breathing following heliox administration (2, $3,26,27,33,46)$. It was reasoned that, if, during exercise while subjects breathed heliox or pure oxygen, respiratory muscle blood flow was less than that during air breathing and quadriceps muscle blood flow was concomitantly increased, then this would point toward a potential redistribution of blood flow from the respiratory to the locomotor muscle.

\section{MATERIALS AND METHODS}

Study subjects. Ten patients with clinically stable COPD participated in the study according to the following inclusion criteria: 1) a postbronchodilator forced expiratory volume in $1 \mathrm{~s}\left(\mathrm{FEV}_{1}\right)<60 \%$ predicted without significant reversibility $(<12 \%$ change of the initial $\mathrm{FEV}_{1}$ value or $<200 \mathrm{ml}$ ) and 2) optimal medical therapy according to Global Initiative for Chronic Obstructive Lung Disease (15). Exclusion criteria included clinically manifest cor pulmonale, cardiovascular illness, musculoskeletal abnormalities, or other diseases that could contribute to exercise limitation, engagement in any pulmonary rehabilitation program in the last $6 \mathrm{mo}$, and any hospital admission or COPD exacerbation within the previous $8 \mathrm{wk}$. As the present study was originally designed with a twofold purpose in mind, the study population herein $(n=10)$ constitutes part of a larger patient population $(n=12)$ whose demographic and exercise performance characteristics have been published elsewhere (48). This disparity in subject population is due to the inconsistency of reliable abdominal muscle blood flow measurements in two subjects. The study was approved by the University Hospital Ethics Committee and was conducted in accordance with the guidelines of the Declaration of Helsinki. Before participation in the study, all patients were informed of any risks and discomforts associated with the experiments and gave written, signed, informed consent.

Experimental design. The present study was originally designed with a twofold purpose: 1) to investigate whether oxygen or heliox administration enhances cerebral cortex oxygen delivery in patients with COPD (48) and 2) to justify whether improvement in exercise capacity documented following oxygen or heliox administration occurs on the basis of blood flow redistribution from the respiratory to the locomotor muscles. Hence, some amount of information of the present study has been published elsewhere (48).

Experiments were conducted in two visits. In visit 1, patients underwent an incremental exercise test to the limit of tolerance [peak work rate $\left.\left(\mathrm{WR}_{\text {peak }}\right)\right]$ while breathing room air. In visit 2 , patients undertook three constant-load exercise tests, each at the same work rate $\left(75 \% \mathrm{WR}_{\text {peak }}\right)$ while breathing room air and then at the same workload, breathing either normoxic heliox (helium 79\% and oxygen $21 \%$ ) or $100 \%$ oxygen, the latter two in balanced order.

Preliminary assessment. All patients underwent the following baseline measurements: anthropometric indices, pulmonary function parameters, 6-min walking distance, and quadriceps muscle strength. Body composition was estimated by a bioelectric impedance device (BF 907; Maltron, Essex, UK). Fat-free mass (FFM) index was obtained by dividing FFM in kilograms by height. Spirometry and single breath transfer factor for carbon dioxide were measured according to the ATS/ERS standards (28). Postbronchodilator static lung volumes were assessed using whole body plethysmography, whereas maximal inspiratory and expiratory pressures were measured using a differential pressure transducer. A 6-min walking test was performed twice according to ATS guidelines (4). Quadriceps muscle strength was assessed using the maximal isometric voluntary contraction technique of the knee extensors following a standardized protocol (42).

Visit 1: incremental testing. In visit 1, the incremental exercise tests were performed on an electromagnetically braked cycle ergometer as previously described (48). During the protocol, patients performed consecutive inspiratory capacity (IC) maneuvers to identify the degree of dynamic lung hyperinflation.

Visit 2: time to exhaustion at $75 \% W_{\text {peak }}$ breathing air, heliox, and $100 \% \mathrm{O}_{2}$. In visit 2, the first constant-load exercise test was on room air, and the other two were while subjects breathed, in balanced order, either $100 \%$ oxygen or normoxic heliox (i.e., $\mathrm{He} 79 \%, \mathrm{O}_{2}$ $21 \%$ ). The three tests were each separated by $120 \mathrm{~min}$ of rest, and, before each, patients warmed up for $5 \mathrm{~min}$ by means of unloaded cycling. During each test, patients were asked to pedal for as long as possible against the constant load to the limit of tolerance (exhaustion). Exhaustion was defined as the time point at which the patients signaled the inability to continue exercising or could not maintain the required pedaling rate $(50-60 \mathrm{revolution} / \mathrm{min})$ despite being encouraged by the investigators. Heliox and $100 \% \mathrm{O}_{2}$ were administered by having subjects inspire from a Douglas bag that was connected to the inspiratory port of a non-re-breathing two-way valve by wide-bore tubing. The same apparatus was utilized during room air breathing to ensure that patients were blinded to the inspired gas mixture each time. During exercise, intercostal, abdominal, and quadriceps muscle blood flow was assessed by near-infrared spectroscopy (NIRS) using the light-absorbing tracer indocyanine green (ICG) dye as indicator, while cardiac output was measured by the standard dye dilution method using ICG (5). The same ICG injection was used for all four of these flow measurements. Arterial blood gases were measured at rest and exhaustion during the final minute or so of each test. As endurance time was expected to be significantly prolonged while subjects breathed pure oxygen or normoxic heliox $(2,3,23,26,33$, 34 ), measurements during these trials were also performed at the time point where exercise in room air was terminated (i.e., at isotime) to detect whether potential differences in oxygen delivery at isotime could, in part, explain differences in endurance time while subjects breathed oxygen or heliox. Therefore, exercise tests on room air were executed always first, and the other two exercise tests on oxygen or heliox followed in balanced order.

Subject preparation. Subjects were prepared with superficial venous and radial arterial catheters. Using local anesthesia (2\% lidocaine) and sterile technique, identical catheters were introduced percutaneously into the right forearm vein and the right radial artery, both oriented in the proximal direction. The catheters were used 1) to collect arterial blood samples, 2) to inject ICG dye into the venous line, and 3) to continuously sample arterial blood after each ICG injection for cardiac output measurement and muscle blood flow calculation. The catheters were kept patent throughout the experiment by periodic flushing with heparinized $(1 \mathrm{U} / \mathrm{ml})$ saline.

Ventilatory measurements. During each constant-load exercise test, recordings of pulmonary gas exchange and ventilatory variables were performed breath by breath as during the preliminary testing. Air flow was measured with a hot wire pneumotachograph (Vmax 229; Sensor Medics, San Diego, CA) near the mouthpiece, and tidal volume changes were obtained by integrating the flow signal. Before each protocol, pneumotachograph and gas analyzers of the system (Vmax 229; Sensor Medics) were calibrated with the experimental gas mixture.

Cardiac output and arterial blood pressure. Cardiac output was determined by the dye dilution method (12), using known volumes of ICG $(1.0 \mathrm{ml}$ containing $5 \mathrm{mg})$ injected into the right forearm vein followed by a rapid 10-ml flush of isotonic saline. Blood was withdrawn from the right radial artery using an automated pump (Harvard Apparatus, Holliston, MA) at $20 \mathrm{ml} / \mathrm{min}$ through a linear photodensitometer (Pulsion ICG; ViCare Medical, Birkerod, Denmark) connected to a cardiac output computer (CO-10; Waters, Rochester, $\mathrm{MN}$ ) through a closed-loop, sterile-tubing system, as previously described $(16,44)$. The blood was reinfused into the forearm vein immediately upon completion of each measurement. The cardiac output computer was connected to a data acquisition system (DI-720; Dataq, Akron, $\mathrm{OH})$. Data were sampled at $100 \mathrm{~Hz}$ and stored on a computer for subsequent analysis. To remove the influence of dye recirculation, 
ICG curves were processed in the usual way. The downslope of the curve was plotted logarithmically, and the linear part was fit using only those data before recirculation. This linear fit was then extrapolated to estimate the recirculation-free remaining downslope during the time of recirculation. The resulting curve was integrated over time to yield the mean arterial ICG concentration. Cardiac output was calculated as the ratio of ICG mass injected to the mean arterial ICG concentration over the time interval of the curve and expressed as liters per minute. ICG calibration curves were obtained following each experiment by measuring the raw voltage deflection from three $20-\mathrm{ml}$ blood samples containing various concentrations of ICG. Calibrations at each concentration were performed two to three times to ensure linearity and consistency, as previously described (44). Arterial blood pressure was measured invasively through the right radial artery using a Nihon Kohden monitor (Life Scope i BSM-2303; Nihon, Kohden, Japan). Systemic vascular conductance was calculated by dividing cardiac output by mean arterial blood pressure.

Muscle blood flow by NIRS. To measure intercostal, abdominal, and quadriceps muscle blood flow, three sets of NIRS optodes were placed on the skin over the left seventh intercostal space at the midaxillary line, over the upper rectus abdominus, and over the left vastus lateralis muscle 10-12 cm above the knee, respectively, and secured using double-sided adhesive tape. The left intercostal space was used to avoid potential blood flow contributions from the liver on the right side of the body. The optode separation distance was $4 \mathrm{~cm}$, corresponding to a penetration depth of $\sim 2 \mathrm{~cm}$. Optodes were connected to NIRO 200 spectrophotometers (Hamamatsu Photonics, Hamamatsu, Japan) to measure ICG concentration following the same 5-mg bolus injection of ICG used for cardiac output assessment. Tissue microcirculatory ICG was detected transcutaneously by measuring light attenuation with NIRS at 775-, 813-, and 850-nm wavelengths and analyzed using an algorithm incorporating the Modified Beer-Lambert Law $(5,13,20,43)$, as previously described (16). Because the measured light attenuation in the tissue is influenced by ICG and oxy- and deoxyhemoglobin, the independent contribution of ICG to the light absorption signal was isolated using a matrix operation (MATLAB). The matrix operation incorporates path length-specific extinction coefficients for each of the light-absorbing chromophores [hemoglobin + myoglobin $(\mathrm{Hb}+\mathrm{Mb})$ and ICG] at each wavelength employed by the NIRS machine (Hamamatsu Photonics).

Blood flow under each optode was calculated from the rate of tissue ICG accumulation over time measured by NIRS according to the Sapirstein principle (38), as previously described by Boushel et al. (5). Accordingly, after a rapid intravenous bolus injection of ICG, the rate of appearance of ICG in a region of muscle depends on blood flow. We therefore measured the appearance rate of ICG under each of the three optodes by NIRS after a bolus injection and calculated the regional blood flow using the following equation: Blood flow $[\mathrm{ml} \cdot(100$ $\left.\mathrm{g} \cdot \min )^{-1}\right]=\left(k \cdot[\mathrm{ICG}]_{m} \cdot t\right) /\left(\int_{o}^{t}[\mathrm{ICG}]_{a} d t\right)$, where $k$ includes the molecular weight of ICG for the conversion of ICG in moles to grams per liter and the estimated muscle density for conversion of tissue volume to tissue weight; $[\mathrm{ICG}]_{m}$ is the accumulation of ICG in tissue over time $t$ expressed in micromoles per liter; and $\int^{t}{ }_{o}[\mathrm{ICG}]_{a} d t$ is the time integral of the arterial ICG concentration expressed in milligrams per liter (5). The ICG calibration procedure, as described for cardiac output, was also used to quantify the input function for calculation of the regional tissue blood flow with NIRS.

Systemic, quadriceps, intercostal, and abdominal muscle oxygen delivery were calculated as the product of the appropriate blood flow (cardiac output, regional muscle blood flows) and arterial oxygen content, respectively.

Arterial blood analysis and calculations. Percentage arterial oxygen saturation $\left(\mathrm{SaO}_{2}\right)$, arterial tensions of $\mathrm{O}_{2}\left(\mathrm{PaO}_{2}\right)$ and $\mathrm{CO}_{2}$ $\left(\mathrm{PaCO}_{2}\right), \mathrm{pH}, \mathrm{Hb}$ concentration, and lactate concentration were measured from 2-ml blood samples using a blood gas analyzer combined with a cooximeter (ABL 625; Radiometer, Copenhagen, Denmark). Arterial $\mathrm{O}_{2}$ content $\left(\mathrm{CaO}_{2}\right)$ was computed $\left[\mathrm{CaO}_{2}=(1.34 \times \mathrm{Hb} \times\right.$
$\left.\left.\mathrm{SaO}_{2}\right)+\left(0.003 \times \mathrm{PaO}_{2}\right)\right]$. The blood gas analyzer was autocalibrated every $2 \mathrm{~h}$ throughout the day, and calibrating gases of known concentrations were run before each set of measurements.

Statistical analysis. Data are reported as means \pm SE unless otherwise stated. The minimum sample size was calculated on the basis of $80 \%$ power and a two-sided 0.05 significance level. The sample size capable of detecting between-condition (i.e., room air, heliox, and $100 \%$ oxygen) difference of $30 \%$ was estimated for the change in intercostal muscle blood flow at $75 \% \mathrm{WR}_{\text {peak }}$ using the standard deviations from our previous study (46). Specifically, data from a previous study of our group in COPD (46) in which we used the same technique for measuring muscle blood flow as in the present study (i.e., NIRS-ICG) revealed a mean increase of $1.8 \mathrm{ml} \cdot \mathrm{min}^{-1} \cdot 100$ $\mathrm{g}^{-1}$ or $30 \%$ in intercostal muscle blood flow while subjects breathed heliox compared with room air breathing during exercise at $75 \%$ $\mathrm{WR}_{\text {peak }}$, i.e., the work rate also applied in the present study. The minimal sample size was calculated to be eight patients. One-way ANOVA with repeated measures was used to identify statistically significant differences across the three experimental tests at isotime and across different time points (i.e., rest, isotime, exhaustion) within each constant-load exercise. When ANOVA detected statistical significance, pairwise differences were identified using Tukey's honestly significant difference post hoc procedure. Data were analyzed using the SPSS statistical program, version 18 (SPSS, Chicago, IL). The level of significance was set at $P<0.05$.

\section{RESULTS}

Subject characteristics. Subject characteristics are shown in Table 1. As anticipated from the inclusion criteria, patients had moderate to severe airway obstruction with increased static lung volumes, moderate to severe reduction in carbon monoxide diffusion capacity, and mildly reduced arterial oxygen tension (Table 1). In addition, patients had normal body mass index without occurrence of muscle wasting as defined by FFM index. Five, three, and two patients had GOLD spirometric level 2, 3, and 4, respectively; three, two, three, and two patients were GOLD category A, B, C, and D, respectively (15).

Maximal exercise and functional capacity. Patients exhibited reduced maximal exercise capacity during incremental exercise test with moderate hemoglobin desaturation and impaired functional capacity as identified by covered distance of 6-min walking and quadriceps muscle strength (Table 2). During constant-load exercise at $75 \% \mathrm{WR}_{\text {peak }}$, time to exhaustion while subjects breathed room air was less than for heliox or oxygen (Table 3).

Central hemodynamic responses. Cardiac output, stroke volume, and heart rate were similar at rest during room air, oxygen, and heliox breathing but during exercise increased from rest in all three conditions $(P<0.01)$ (Fig. 1, $A-C)$. At isotime while subjects breathed heliox, cardiac output tended to be greater compared with room air or oxygen breathing $(9.2 \pm 0.5$ vs. $8.5 \pm 0.6$ and $8.2 \pm 0.7 \mathrm{~s}$, respectively; $P=$ 0.089) (Fig. 1A). At exhaustion, cardiac output was not different between the three conditions (Fig. 1A). Stroke volume was greater while subjects breathed heliox compared with room air at isotime $(P=0.031)$, whereas at exhaustion it was greater when they breathed pure oxygen compared with room air $(P=$ 0.045 ) (Fig. $1 B$ ). Heart rate did not differ between the three conditions (Fig. 1C). Systemic vascular conductance was similar at rest and increased during exercise in all conditions $(P<$ 0.001) (Fig. 1D). Interestingly, at isotime, systemic vascular conductance was greater on heliox breathing compared with 
Table 1. Demographic, anthropometric, and baseline pulmonary function data

\begin{tabular}{|c|c|}
\hline Variable & Data for 10 Subjects \\
\hline \multicolumn{2}{|c|}{ Demographic/anthropometric } \\
\hline Age, yr & $65 \pm 6$ \\
\hline Sex, $\mathrm{m} / \mathrm{f}$ & $8 / 2$ \\
\hline Height, cm & $172 \pm 10$ \\
\hline Weight, $\mathrm{kg}$ & $74 \pm 8$ \\
\hline Body mass index, $\mathrm{kg} / \mathrm{m}^{2}$ & $25.0 \pm 2.5$ \\
\hline Fat free mass index, $\mathrm{kg} / \mathrm{m}^{2}$ & $18.1 \pm 2.1$ \\
\hline \multicolumn{2}{|c|}{ Pulmonary function } \\
\hline $\mathrm{FEV}_{1}, 1$ & $1.34 \pm 0.5$ \\
\hline $\mathrm{FEV}_{1}, \%$ predicted & $46 \pm 12$ \\
\hline FVC, 1 & $2.9 \pm 0.6$ \\
\hline FVC, $\%$ predicted & $80 \pm 12$ \\
\hline $\mathrm{FEV}_{1} / \mathrm{FVC}$ & $0.44 \pm 0.18$ \\
\hline IC, 1 & $2.4 \pm 16$ \\
\hline IC, $\%$ predicted & $81 \pm 7$ \\
\hline $\mathrm{RV}, 1$ & $4.3 \pm 1.1$ \\
\hline $\mathrm{RV}, \%$ predicted & $197 \pm 15$ \\
\hline FRC, 1 & $5.3 \pm 1.1$ \\
\hline FRC, $\%$ predicted & $172 \pm 24$ \\
\hline TLC, 1 & $7.8 \pm 1.8$ \\
\hline TLC, $\%$ predicted & $123 \pm 13$ \\
\hline RV/TLC, \% predicted & $159 \pm 29$ \\
\hline IC/TLC & $0.31 \pm 0.07$ \\
\hline $\mathrm{TL}_{\mathrm{CO}}, \%$ predicted & $41 \pm 9$ \\
\hline $\mathrm{MIP}, \mathrm{cmH}_{2} \mathrm{O}$ & $-71 \pm 25$ \\
\hline MIP, \% predicted & $70 \pm 24$ \\
\hline $\mathrm{MEP}, \mathrm{cmH}_{2} \mathrm{O}$ & $80 \pm 22$ \\
\hline MEP, \% predicted & $42 \pm 11$ \\
\hline Resting $\mathrm{PaO}_{2}, \mathrm{mmHg}$ & $73 \pm 9$ \\
\hline Resting $\mathrm{PaCO}_{2}, \mathrm{mmHg}$ & $38 \pm 6$ \\
\hline Resting $\mathrm{SaO}_{2}, \%$ & $95 \pm 1$ \\
\hline
\end{tabular}

Values are expressed as means $\pm \mathrm{SD}$ for 10 subjects. $\mathrm{FEV}_{1}$, forced expiratory volume in $1 \mathrm{~s}$; FVC, forced vital capacity; IC, inspiratory capacity; $\mathrm{RV}$, residual volume; FRC, functional residual capacity; TLC, total lung capacity; TLCO, diffusing capacity of the lung for carbon monoxide; MIP, maximal inspiratory pressure; MEP, maximal expiratory pressure; $\mathrm{PaO}_{2}$, partial pressure of arterial oxygen; $\mathrm{PaCO}_{2}$, partial pressure of arterial carbon dioxide; $\mathrm{SaO}_{2}$, arterial oxygen saturation.

both air and oxygen $(P<0.01)$, whereas, at exhaustion, it did not differ across the three conditions (Fig. 1D).

Quadriceps muscle hemodynamic responses. Quadriceps muscle blood flow was similar at rest during room air, oxygen, and heliox breathing and significantly increased during exercise compared with rest across all three conditions $(P<0.001)$ (Fig. 2A). At both isotime and exhaustion, quadriceps muscle blood flow during heliox breathing was greater compared with room air and oxygen breathing $(P<0.01$ for all) (Fig. $2 A)$. Furthermore, no difference in quadriceps muscle blood flow between air and oxygen breathing was present either at isotime or exhaustion (Fig. 2A). Quadriceps muscle oxygen delivery was similar at rest during air, oxygen, and heliox breathing and significantly increased during exercise from rest in all three conditions $(P<0.001)$ (Fig. $2 D)$. At isotime and exhaustion, quadriceps muscle oxygen delivery during heliox and oxygen breathing was greater compared with room air breathing $(P<$ 0.01 for both) (Fig. $2 D$ ).

Respiratory muscle hemodynamic responses. Intercostal and abdominal wall muscle blood flow was similar at rest across all three conditions and increased during exercise compared with rest only during heliox breathing $(P<0.05)$ (Fig. $2, B$ and $C$ ).
At isotime and exhaustion, intercostal and abdominal muscle blood flow during heliox breathing was greater compared with both room air and oxygen breathing $(P<0.05$ for all) (Fig. 2, $B$ and $C$ ). No significant differences in intercostal or abdominal muscle blood flow between air and oxygen breathing were detected at isotime or exhaustion (Fig. 2, $B$ and $C$ ). Intercostal and abdominal muscle oxygen delivery was comparable at rest across the three conditions and increased during exercise compared with rest only during heliox breathing $(P<0.05)$ (Fig. $2, E$ and $F$ ). At isotime and exhaustion, intercostal and abdominal muscle oxygen delivery during heliox and oxygen breathing was greater than during room air breathing $(P<0.01$ for both) (Fig. 2, $E$ and $F$ ). Intercostal muscle oxygen delivery was also greater during heliox compared with oxygen breathing at isotime and exhaustion $(P<0.05$ for both) (Fig. $2 E)$.

Arterial blood gas responses. At rest, arterial oxygen content $\left(\mathrm{CaO}_{2}\right)$ was lower in room air compared with oxygen $(P<$ $0.0001)$ and heliox $(P=0.033)$, and it was also lower during heliox compared with oxygen breathing $(P<0.0001)$ (Fig. 3A). During exercise, $\mathrm{CaO}_{2}$ did not change from rest in either condition. At isotime and exhaustion, $\mathrm{CaO}_{2}$ during pure oxygen breathing was greater compared with both room air and heliox breathing $(P<0.0001$ for all) (Fig. 3A). Systemic oxygen delivery was similar at rest and during exercise increased in all three conditions $(P<0.001)$ (Fig. 3B). Systemic oxygen delivery did not differ across the three conditions at isotime, but, at exhaustion, it was greater on oxygen compared with both air and heliox breathing $(P=0.0001)$ (Fig. $3 B)$. $\mathrm{PaO}_{2}$ (Fig. 3C), $\mathrm{PaCO}_{2}$ (Fig. 3D), and $\mathrm{SaO}_{2}$ (Table 3) were greater, whereas $\mathrm{pH}$ (Fig. $3 E$ ) was lower in oxygen compared with air and heliox breathing at both isotime and exhaustion $\left(P<0.01\right.$ for all). In addition, $\mathrm{PaCO}_{2}$ at exhaustion was lower and $\mathrm{SaO}_{2}$ at both isotime and exhaustion was greater during heliox compared with room air breathing $(P<0.05$ for both).

Table 2. Peak exercise data and functional capacity

\begin{tabular}{lc}
\hline \multicolumn{1}{c}{ Variable } & Data for 10 Subjects \\
\hline $\mathrm{WR}_{\text {peak }}, \mathrm{W}$ & $65 \pm 17$ \\
$\mathrm{VO}_{2 \text { peak }}, 1 / \mathrm{min}$ & $1.26 \pm 0.4$ \\
$\mathrm{VO}_{2 \text { peak }}, \mathrm{ml} / \mathrm{kg}$ per min & $17.2 \pm 3.5$ \\
$\mathrm{VO}_{2 \text { peak }}, \%$ predicted & $67 \pm 15$ \\
$\mathrm{AT}, \%$ of $\mathrm{VO}_{2 \text { peak }}$ & $52 \pm 9$ \\
$\mathrm{HR}_{\text {peak }}$, beats/min & $116 \pm 17$ \\
$\mathrm{HR}_{\text {peak }}, \%$ predicted & $75 \pm 9$ \\
$\mathrm{~V}_{\text {Epeak }}, 1 / \mathrm{min}$ & $44 \pm 12$ \\
$\mathrm{~V}_{\text {Epeak }} / \mathrm{MVV}$ & $0.85 \pm 0.11$ \\
$\mathrm{~V}_{\text {Epeak }} / \mathrm{VCO}$ & $39 \pm 9$ \\
$\mathrm{~V}_{\text {Tpeak }}, 1$ & $1.38 \pm 0.3$ \\
$\mathrm{f}_{\text {peak }}$, breaths/min & $32.0 \pm 2.0$ \\
$\Delta \mathrm{IC}$, liters & $0.236 \pm 0.03$ \\
SpO & $\%$ \\
Borg dyspnoea scores & $87 \pm 3$ \\
Borg leg effort scores & $7 \pm 2$ \\
6-Min walking test, $\mathrm{m}$ & $6 \pm 2$ \\
6-Min walking test, $\%$ predicted & $395 \pm 40$ \\
Quadriceps muscle force, kg & $68 \pm 10$ \\
Quadriceps muscle force, $\%$ predicted & $28 \pm 6$ \\
\hline
\end{tabular}

Values are expressed as means $\pm \mathrm{SD}$ for 10 subjects. $\mathrm{WR}_{\text {peak }}$, peak work rate; $\mathrm{VO}_{2 \text { peak }}$, peak oxygen uptake; $\mathrm{VCO}_{2 \text { peak }}$, peak carbon dioxide output; $\mathrm{AT}$, anaerobic threshold; $\mathrm{HR}_{\text {peak }}$, peak heart rate; $\mathrm{V}_{\text {Epeak }}$, peak minute ventilation; $\mathrm{V}_{\text {Tpeak}}$, peak tidal volume; MVV, maximal voluntary ventilation; $f_{\text {peak }}$, peak breathing frequency; $\Delta \mathrm{IC}$, decrease in peak inspiratory capacity compared with baseline; $\mathrm{SpO}_{2}$, arterial oxygen saturation measured by pulse oximetry. 
Table 3. Constant load exercise data at $75 \%$ WR peak

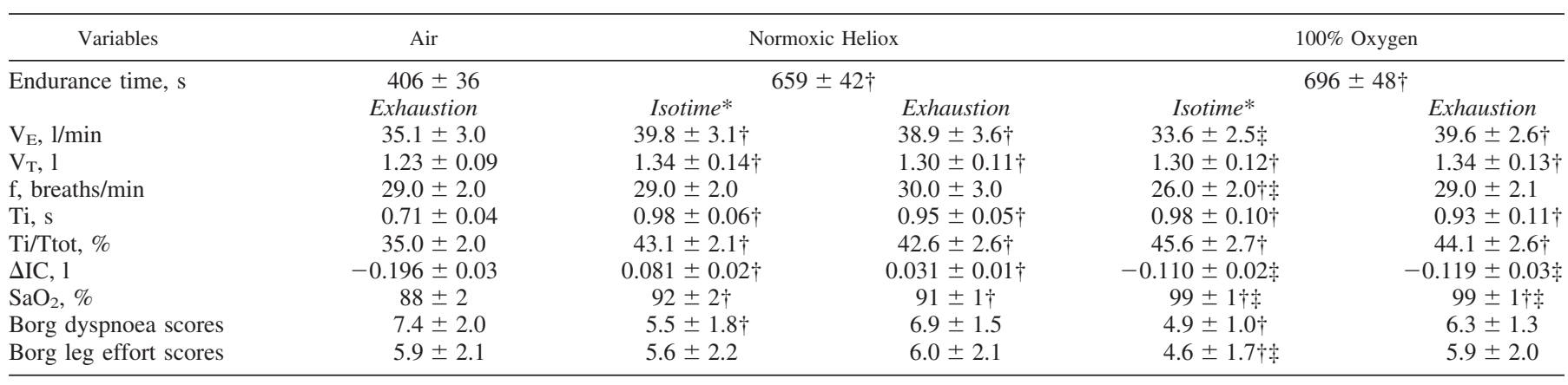

Values are expressed as means $\pm \mathrm{SE}$ for 10 subjects. $\mathrm{WR}_{\text {peak, }}$, peak work rate at the preliminary incremental test in room air. $\mathrm{V}_{\mathrm{E}}$, minute ventilation; $\mathrm{V}_{\mathrm{T}}$, tidal volume; $\mathrm{f}$, breathing frequency; Ti, time of inspiration; Ti/Tot, duty cycle of inspiration; $\Delta \mathrm{IC}$, change in inspiratory capacity compared with baseline; *Isotime data are those obtained on normoxic heliox and $100 \%$ oxygen at the same time as at exhaustion on room air. $\dagger P<0.05$ vs. exhaustion in room air. $\ddagger P<0.05$ vs. normoxic heliox at the same time point of exercise.

At isotime and exhaustion, lactate concentration during heliox and oxygen breathing was lower than during room air breathing $(P<0.05$ for both) (Fig. $3 F)$. No significant differences in lactate concentration between heliox and oxygen breathing were detected at isotime or exhaustion (Fig. $3 F$ ).

Symptoms and ventilatory responses. Constant-load exercise data are shown in Table 3. At isotime, minute ventilation while subjects breathed heliox was greater compared with room air and oxygen $(P<0.01)$. This was due to higher tidal volume during heliox compared with air breathing and lower breathing frequency during oxygen compared with heliox breathing despite a comparably increased tidal volume on oxygen. At exhaustion, minute ventilation was higher while subjects breathed heliox and oxygen compared with room air $(P<$ 0.01 ), and this response was mostly due to greater tidal volume, as breathing frequency was almost identical. At isotime and exhaustion, inspiratory time and duty cycle of inspiration were greater while subjects breathed heliox and oxygen compared with room air $(P<0.01$ for all $)$. At isotime and exhaustion, while subjects breathed heliox, IC compared with baseline was greater than breathing room or oxygen $(P<$ 0.005 for all). Dyspnoea sensations at isotime were lower during exercise on heliox and oxygen compared with room air, whereas leg discomfort during oxygen breathing was lower compared with heliox and room air breathing at isotime.

\section{DISCUSSION}

This is the first study to investigate the effects of both heliox and oxygen administration on respiratory muscle blood flow. The major finding of the present study was that, during exercise with oxygen (designed to primarily enhance arterial $\mathrm{O}_{2}$ concentration but also to reduce respiratory muscle load) or heliox (designed to chiefly reduce the mechanical work of breathing but not directly also increase arterial $\mathrm{O}_{2}$ concentration), there was no decrease in respiratory (abdominal or intercostal) muscle blood flow compared with exercise in room air. In fact, on heliox, respiratory muscle blood flow was greater than on air. These findings dispute the theory of blood flow redistribution from the respiratory muscles to the legs as
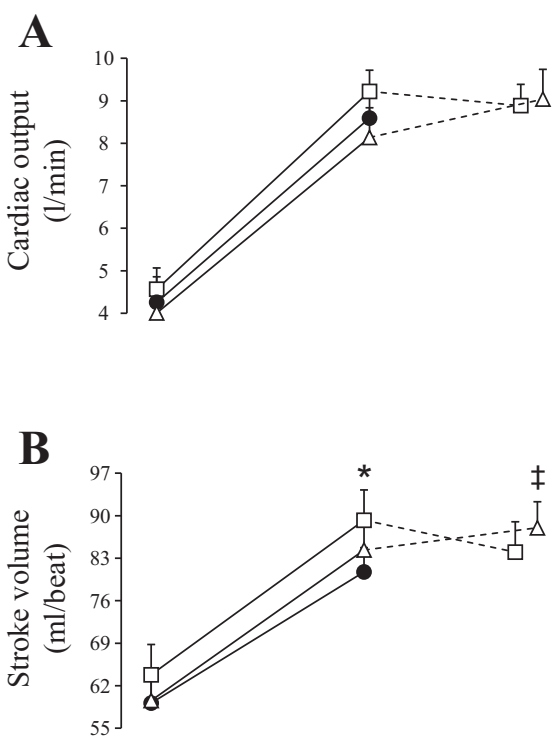

Rest

Iso-Time

Exhaustion

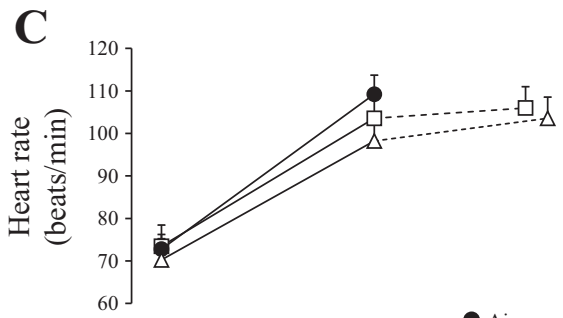

Air $\triangle 100 \% \mathrm{O}_{2}$

D

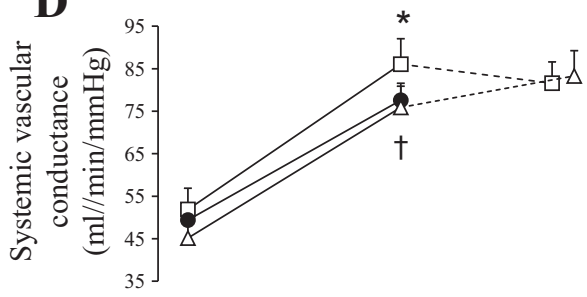

Rest
Fig. 1. Central hemodynamic responses. A: cardiac output. $B$ : stroke volume. $C$ : heart rate. $D$ : systemic vascular conductance recorded at rest, at the time of exhaustion in room air (iso-time), and at the limit of exercise tolerance (exhaustion) while subjects breathed normoxic heliox ( $\square$ ), 100\% oxygen $(\triangle)$, or room air $(\bullet)$. Values are means \pm SE for 10 subjects. Isotime data are those obtained on normoxic heliox or $100 \%$ oxygen at the same time as at exhaustion on room air. $* P<0.05$ compared with room air at the same time point of exercise. $\dagger P<0.05$ compared with normoxic heliox at the same time point of exercise. $\ddagger P<0.05$ compared with exhaustion in room air. Significant differences between data at isotime or exhaustion and rest are not indicated on the figure. 
Fig. 2. Quadriceps, intercostal, and abdominal muscle hemodynamic responses. A: quadriceps muscle blood flow. $B$ : intercostal muscle blood flow. $C$ : abdominal muscle blood flow. $D$ : quadriceps muscle oxygen delivery. $E$ : intercostal muscle oxygen delivery. $F$ : abdominal muscle oxygen delivery recorded at rest, at the time of exhaustion in room air (iso-time), and at the limit of exercise tolerance (exhaustion) while subjects breathed normoxic heliox $(\square), 100 \%$ oxygen $(\triangle)$, or room air $(\bullet)$. Values are means \pm SE for 10 subjects. Isotime data are those obtained on normoxic heliox or $100 \%$ oxygen at the same time as at exhaustion on room air. $* P<0.05$ compared with room air at the same time point of exercise. $\dagger P<0.05$ compared with normoxic heliox at the same time point of exercise. $\ddagger P<0.05$ compared with exhaustion in room air. Significant differences between data at isotime or exhaustion and rest are not indicated on the figure.
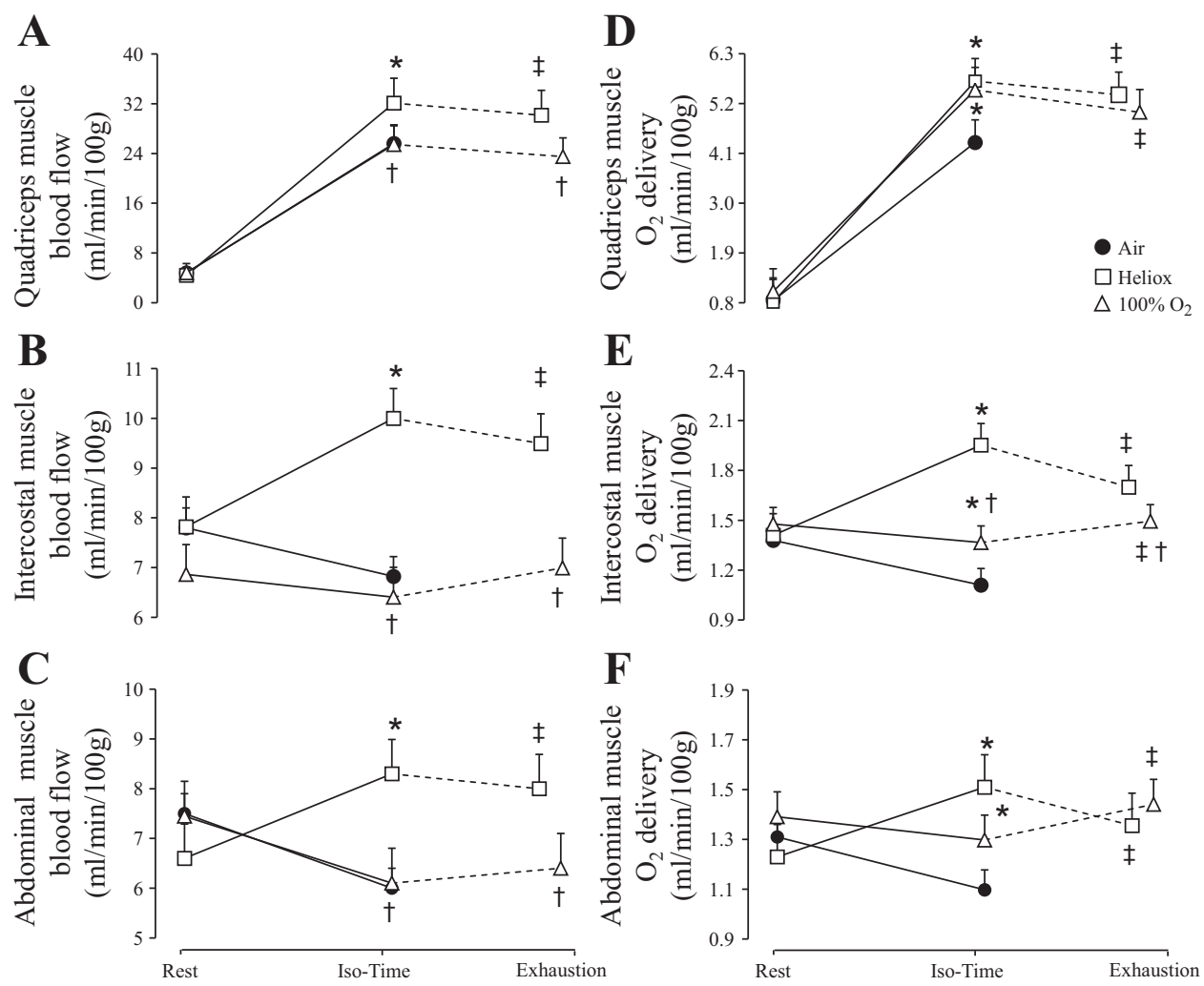

the basis for improved endurance capacity under these conditions $(10,17,18)$. However, on both heliox and $100 \% \mathrm{O}_{2}$, constant-load endurance times were similar and considerably greater than on air (Table 3). Figure 2 shows that quadriceps $\mathrm{O}_{2}$ delivery was similar on heliox and $100 \% \mathrm{O}_{2}$, albeit for different reasons (greater blood flow with heliox, higher arterial $\mathrm{O}_{2}$ concentration with $\mathrm{O}_{2}$ breathing) with values under both conditions significantly greater than on air. This suggests that a common basis for enhanced exercise performance may be improved $\mathrm{O}_{2}$ availability afforded by these interventions.

Study originality. The novelty of the present study derives from the fact that we examined the hypothesis of blood flow redistribution from respiratory to leg muscles during exercise in patients with COPD $(10,17,18)$ by applying two methods that are known to reduce the work of breathing and increase leg muscle oxygen delivery $(26,27,46)$, namely heliox and oxygen supplementation $(2,26,46)$, while concomitantly performing direct and simultaneous measurements of both respiratory and leg muscle blood flow. We argued that, if there was blood flow redistribution between the respiratory and the locomotor muscles, then we should have observed a reduction in respiratory muscle blood flow and a concomitant increase in locomotor muscle blood flow. Importantly, the design of the study allowed us to perform for the first time simultaneous measurements of inspiratory and expiratory muscle blood flow measurements in patients with COPD by utilizing NIRS in association with the light-absorbing tracer ICG (5). Because we were unable to directly measure blood flow in the diaphragm with the NIRS technique $(16,45)$, we focused our efforts on measuring blood flow on other respiratory muscles, namely the intercostal and abdominal muscles. In patients with COPD, as the degree of dynamic lung hyperinflation gradually increases during exercise, the pressure generated by the diaphragm decreases, and the act of inspiration is more dependent on the rib cage inspiratory muscles such as the intercostal muscles (8). In addition, the abdominal muscles are the major muscles of expiration and recruited by patients with COPD even at rest (29), whereas their efficiency is not affected as much by the occurrence of lung hyperinflation during exercise compared with the diaphragm (9).

The concept of redistribution. The concept of blood flow redistribution from the respiratory to the locomotor muscles during exercise came from studies in healthy subjects showing reductions in leg muscle blood flow with respiratory muscle loading $(17,18)$. The reduction in leg muscle blood flow was attributed to increased sympathetic vasoconstrictor outflow to the limb muscles upon activation of a metaboreflex secondary to respiratory muscle fatigue (10). Furthermore, studies indirectly supporting the notion of redistribution of blood flow in favor of the respiratory muscles are those showing that patients with severe COPD and increased ventilatory energy requirement during exercise typically exhibit a plateau in leg muscle blood flow despite the increase in workload and whole body oxygen uptake $(27,39)$. This plateau in leg muscle blood flow has been attributed to increased requirement for blood flow by the respiratory muscles although no actual respiratory muscle blood flow measurements were carried out in those studies (27, 39). In addition, in patients with COPD, there could be additional blood flow requirements to support the enhanced metabolic activity caused by stress (i.e., increased catecholamines) and the increased activity of the arm and trunk muscles that primarily stabilize the chest wall. Indeed, enhanced arm and trunk muscle activity contributes to increased ventilation, especially in patients with COPD who have to overcome very 
A
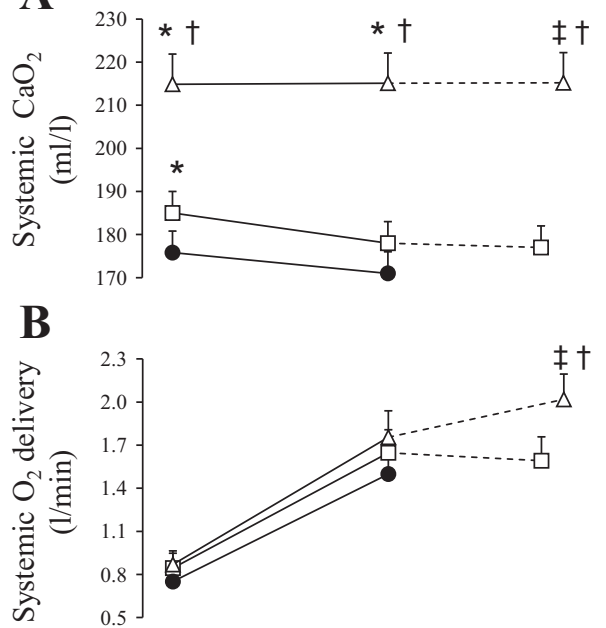

C

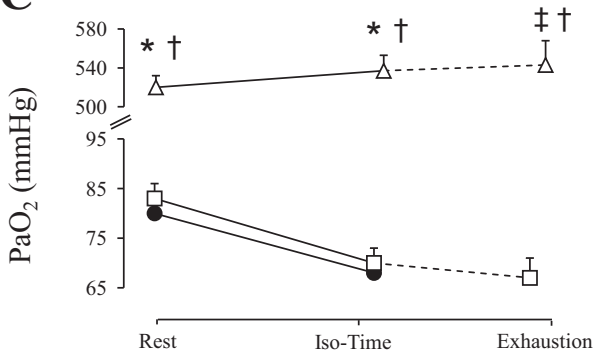

D

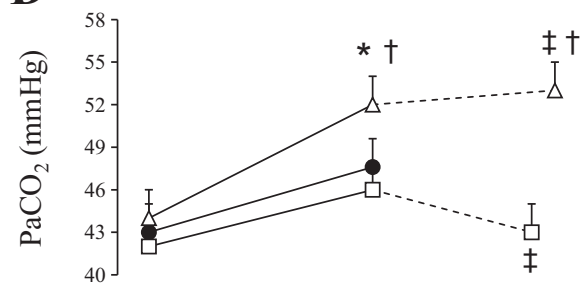

$\mathbf{E}$

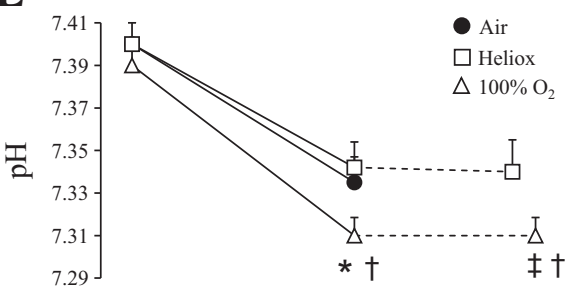

$\mathbf{F}$

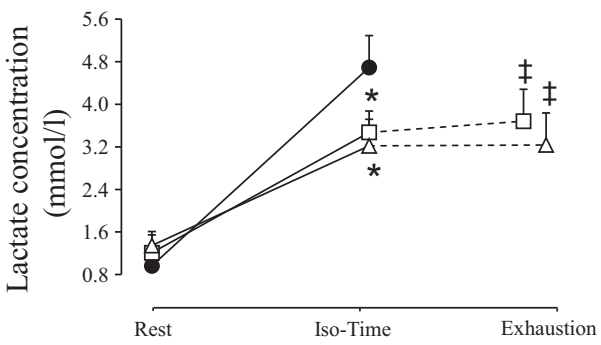

Fig. 3. Arterial blood analysis. A: arterial oxygen content $\left(\mathrm{CaO}_{2}\right)$. B: systemic oxygen delivery. $C$ : arterial $\mathrm{O}_{2}$ pressure $\left(\mathrm{PaO}_{2}\right) . D$ : arterial $\mathrm{CO}_{2}$ pressure $\left(\mathrm{PaCO}_{2}\right)$. E: pH. F: blood lactate concentration recorded at rest, at the time of exhaustion in room air (iso-time), and at the limit of exercise tolerance (exhaustion) while subjects breathed normoxic heliox ( $\square$ ), 100\% oxygen $(\triangle)$, or room air $(\bullet)$. Values are means $\pm \mathrm{SE}$ for 10 subjects. Isotime data are those obtained on normoxic heliox or $100 \%$ oxygen at the same time as at exhaustion on room air. $* P<0.05$ compared with room air at the same time point of exercise. $\dagger P<0.05$ compared with normoxic heliox at the same time point of exercise. $\$ P<0.05$ compared with exhaustion in room air. Significant differences between data at isotime or exhaustion and rest are not indicated on the figure. high levels of respiratory muscle load. Nevertheless, the potentially greater metabolic activity required by the respiratory and stabilizing muscles of the chest wall would be expected to simultaneously increase the demand for muscle perfusion and could therefore partially limit blood flow availability to the leg muscles.

Effect of heliox breathing. In this context, previous studies from our group $(45,46)$ challenged the concept of blood flow redistribution in favor of the respiratory muscles in patients with COPD. We found that, during high-intensity exercise in room air, intercostal muscle blood flow was limited while quadriceps muscle perfusion was preserved (45). In addition, following heliox supplementation causing reduction in respiratory muscle load, intercostal muscle blood flow was not decreased while locomotor muscle blood flow was concomitantly increased compared with exercise in room air (46). In the present study, we also measured blood flow in other respiratory muscles during exercise, namely the abdominal muscles, to identify potential blood flow redistribution secondary to their unloading. Indeed, during high-intensity exercise in patients with COPD, inspiratory muscle work reaches a plateau, whereas expiratory muscle recruitment and pressure-time product continue to increase (21). Furthermore, a recent study revealed that fatigue of the abdominal muscles can develop in patients with COPD exercising at high intensity (19). This is of importance in blood flow regulation, as development of fatigue of the abdominal muscles has been shown to increase sympathetic vasoconstrictor outflow to peripheral muscles, which could promote a reduction in locomotor muscle blood flow (11). Thus, by decreasing the work of the abdominal muscles by heliox administration (46), a reduction in abdominal muscle energy requirement and hence blood flow is expected, which could potentially increase blood flow to the locomotor muscles. The results of the present study do not support such a mechanism because we found that abdominal muscle blood flow was in fact increased following heliox administration (Fig. 2C).

Furthermore, intercostal muscle blood flow may be reduced by local compressive factors associated with increased intramuscular tension $(8,9)$. Accordingly, changes in intercostal muscle fiber orientation following heliox breathing and reduction in dynamic hyperinflation (Table 3) may have diminished intramuscular tension and changed rib cage geometry, thereby decreasing intercostal muscle vascular compression and increasing intercostal blood flow (Fig. 2B). In addition, it has been well documented $(8,9)$ that mitigation of dynamic hyperinflation is associated with lengthening of the diaphragm, resulting in improved generation of a negative pleural pressure (better position of the length-tension relationship). This as well may have contributed to the observed increase in abdominal muscle blood flow during heliox compared with air breathing (Fig. 2C).

Central hemodynamic responses with heliox breathing. The greater respiratory muscle perfusion (Fig. 2, $B$ and $C$ ) following heliox supplementation can be partly attributed to alleviation of disturbances in central hemodynamics imposed by the mechanics of breathing in patients with COPD. Reduced inspiratory and mainly expiratory pressures by heliox administration $(2,26,46)$ may justify the finding of increased stroke volume at isotime (Fig. $1 B$ ) secondary to decreased ventricular afterload and mainly increased venous return, respectively (25, $26,46)$. In addition, heliox breathing by decreasing hyperinflation (Table 3 ) and the pressure-time product for the expira- 
tory abdominal muscles (46) may have collectively decreased the strain imposed on the right heart and thus improved central, peripheral, and respiratory muscle hemodynamic responses. Although the numerical increase in cardiac output by $\sim 8 \%$ at isotime during heliox compared with air breathing (Fig. 1A) failed to reach statistical significance in our relatively small patient group, systemic vascular conductance was greater compared with room air (Fig. 1F). Thus our findings corroborate previous findings obtained during constant-load submaximal or near-maximal exercise in $\operatorname{COPD}(2,7,24,25,26,46)$ in that unloading the respiratory muscles by heliox administration alleviates disturbances in central hemodynamics imposed by the mechanics of breathing in patients with COPD.

Furthermore, direct mechanical factors could have allowed better perfusion of the intercostal (46) and abdominal muscles during heliox breathing. Indeed, decreasing the respiratory effort by heliox breathing may have mitigated local compressive factors associated with increased intramuscular tension and changes in muscle fiber orientation, thus decreasing respiratory muscle vascular compression and increasing respiratory muscle blood flow. Alleviation of these direct mechanical factors during heliox breathing might solely be responsible for increased respiratory muscle perfusion at exhaustion compared with room air breathing (Fig. 2, $B$ and $C$ ) because any advantage in central hemodynamics during heliox breathing was not present at exhaustion (Fig. 1, $A$ and $D$ ).

Effect of oxygen breathing. Previous findings have shown that the metabolic capacity of the lower limb muscles to consume oxygen is not reached at peak exercise during room air breathing (37). Maltais and colleagues (27) found that, in patients with COPD, acute oxygen supplementation during incremental exercise improved peak blood flow to leg muscles and enabled them to perform $20 \%$ more peak external work. However, in that study (27), respiratory muscle blood flow was not measured. In our study, we examined whether a potential improvement in leg muscle blood flow by oxygen supplementation would occur concomitantly to a decrease in respiratory muscle blood flow owing to lower respiratory muscle loading (2). However, we demonstrated that, during oxygen breathing, neither quadriceps nor respiratory muscle blood flow differed compared with room air breathing (Fig. 2, $A-C$ ), but both respiratory (Fig. 2, $E$ and $F$ ) and leg muscle oxygen delivery (Fig. 2D) increased compared with room air breathing due to increased $\mathrm{CaO}_{2}$ (Fig. 3A). Indeed, lack of increase in leg muscle blood flow with oxygen breathing could be attributed to the increase in $\mathrm{CaO}_{2}$ and thus in oxygen delivery to the working muscles $(3,33)$, without necessitating any increase in leg muscle blood flow and redistribution of blood flow from respiratory to locomotor muscles.

The findings that, during exercise, blood flow of intercostal and rectus abdominus muscles does not change (in fact, numerically but not statistically, goes down) from rest while subjects breathe room air support the findings of a previous study by our group (45), which demonstrated restriction of intercostal muscles perfusion but increase of quadriceps muscle blood flow during intense exercise in COPD. Mechanical factors may play a significant role because, in COPD, prolonged expiration with high-expiratory muscle contractile force limits perfusion, just as in cycle exercise where, in the legs, blood flow falls during active contraction and then increases during relaxation each cycle stroke. As far as pure oxygen breathing is concerned, the lack of change in blood flow of both respiratory muscles during exercise might be attributed to the increase in arterial oxygen content and thus in oxygen delivery to the respiratory muscles without necessitating any increase in respiratory muscle blood flow.

Effect on dyspnea sensations. Heliox and pure oxygen breathing reduced dyspnea perception at isotime and prolonged time to exhaustion (Table 3). The most likely known explanation is reduction of the work of breathing, which diminishes dyspnea, thus contributing to the improvement of exercise performance $(2,31,34,40,46)$. Indeed, heliox by reducing turbulent airway resistances and respiratory impedance decreases the total work of breathing because of unloading of inspiratory and mainly expiratory muscles $(26,32,34,46)$. Oxygen administration in turn decreases minute ventilation through a decrease in respiratory drive via inhibition of carotid bodies and/or improved metabolic conditions of the skeletal muscles $(14,31,41)$, thus decreasing dynamic lung hyperinflation and work of breathing. The results of the present study reveal a novel potential mechanism of dyspnea relief during heliox or oxygen breathing by demonstrating increased respiratory muscle oxygen delivery compared with air breathing (Fig. 2, $E$ and $F$ ). In fact, this increase in inspiratory and expiratory muscle oxygen delivery by heliox and oxygen might eliminate or postpone exercise-induced respiratory muscle fatigue $(11,19,35,36)$, relieve dyspnea, and increase exercise capacity.

Study limitations. A potential limitation of the present study was that we did not perform blood flow measurements of the diaphragm to provide a more complete picture of perfusion redistribution of the main respiratory muscle during exercise. The reason was that NIRS optodes cannot be used for measuring blood flow in the diaphragm due to the substantial distance between the sampling point of NIRS on the skin and the diaphragmatic appositional area $(16,45)$ compared with the shorter distance for the intercostals and abdominal muscles. Nonetheless, given that blood flow measurements of the diaphragm in conscious humans at rest and during exercise have never been performed, any assumptions of blood flow redistribution within respiratory muscles during exercise are very speculative. Conclusively, the magnitude of blood flow through the respiratory muscles that we were able to access suggests that redistribution of blood flow from the respiratory to locomotor muscles is not the explanation for better tolerance during heliox or $\mathrm{O}_{2}$ breathing. Secondly, measurements of respiratory muscle loading were not conducted in the present study because we wished to avoid further patient discomfort from esophageal and gastric balloon placement for assessment of esophageal and gastric pressures and because the unloading effects of heliox and oxygen on respiratory muscles during exercise have already been clearly demonstrated by us $(26,46)$ and others (2). Finally, we did not measure pulmonary artery pressures at rest or during exercise in this study and thus cannot evaluate its presence or severity or functional consequence for our results.

Significance. The present study constitutes the first experimental demonstration that the well-documented improvement in exercise capacity following alleviation of respiratory muscle loading by heliox or oxygen administration $(2,3,26,27,33$, 46) does not occur on the basis of blood flow redistribution from the respiratory to locomotor muscles. Instead, exercise 
capacity was increased by a similar time magnitude consequently to the similarly improved locomotor muscle oxygen delivery, albeit for different reasons, namely greater blood flow with heliox and higher arterial $\mathrm{O}_{2}$ concentration with oxygen breathing.

In conclusion, the findings of the present study confirm that reducing the burden on respiration by heliox or oxygen breathing prolongs time to exhaustion during constant-load exercise in patients with COPD, but they do not support the hypothesis that redistribution of blood flow from the respiratory to locomotor muscles is the explanation.

\section{ACKNOWLEDGMENTS}

We thank our subjects for their considerable patience during this intensive and exhausting investigation.

\section{DISCLOSURES}

No conflicts of interest, financial or otherwise, are declared by the authors.

\section{AUTHOR CONTRIBUTIONS}

Author contributions: Z.L., I.V., A.A., H.H., P.D.W., and S.G.Z. conception and design of research; Z.L., I.V., A.A., H.H., H.W., and P.D.W. performed experiments; Z.L., A.A., H.H., H.W., P.D.W., and S.G.Z. analyzed data; Z.L., I.V., A.A., and S.G.Z. interpreted results of experiments; Z.L. and S.G.Z. prepared figures; Z.L., I.V., P.D.W., and S.G.Z. drafted manuscript; Z.L., I.V., A.A., H.H., P.D.W., and S.G.Z. edited and revised manuscript; Z.L., I.V., A.A., H.H., H.W., P.D.W., and S.G.Z. approved final version of manuscript.

\section{REFERENCES}

1. Athanasopoulos D, Louvaris Z, Cherouveim E, Andrianopoulos V, Roussos C, Zakynthinos S, Vogiatzis I. Expiratory muscle loading increases intercostal muscle blood flow during leg exercise in healthy humans. J Appl Physiol 109: 388-395, 2010.

2. Amann M, Regan MS, Kobitary M, Eldridge MW, Boutellier U, Pegelow DF, Dempsey JA. Impact of pulmonary system limitations on leg muscle fatigue in patients with COPD. Am J Physiol Regul Integr Comp Physiol 299: R314-R324, 2010.

3. Ambrossino N, Strambi S. New strategies to improve exercise tolerance in chronic obstructive pulmonary disease. Eur Respir J 24: 313-322, 2004.

4. ATS. ATS statement: guidelines for the six-minute walk test. Am J Respir Crit Care Med 1661: 111-117, 2002.

5. Boushel R, Langberg H, Olesen J, Nowak M, Simonsen L, Bulow J, Kjaer M. Regional blood flow during exercise in humans measured by near-infrared spectroscopy and indocyanine green. J Appl Physiol 89: 1868-1878, 2000.

6. Bye PTP, Esau SA, Levy RO, Shiner RJ, Macklem PT, Martin JG, Pardy RL. Ventilatory muscle function during exercise in air and oxygen in patients with chronic air-flow limitation. Am Rev Respir Dis 132: 236-240, 1985.

7. Chiappa GR, Queiroga F Jr, Meda E, Ferreira LF, Diefenthaeler F, Nunes M, Vaz MA, Machado MC, Nery LE, Neder JA. Heliox improves oxygen delivery and utilization during dynamic exercise in patients with chronic obstructive pulmonary disease. Am J Respir Crit Care Med 179: 1004-1010, 2009.

8. De Troyer A, Pride NB. The chest wall and respiratory muscles in chronic obstructive pulmonary disease. In: The Thorax, edited by $\mathrm{C}$ Roussos. New York, NY: Dekker, 1995, pp. 1975-2006.

9. De Troyer A. Effects of hyperinflation on diaphragm. Eur Respir J 24: 313-322, 2004.

10. Dempsey JA, Romer L, Rodman J, Miller J, Smith C. Consequences of exercise-induced respiratory muscle work. Respir Physiol Neurobiol 151: 242-250, 2006.

11. Derchak PA, Sheel AW, Morgan BJ, Dempsey JA. Effects of expiratory muscle work on muscle sympathetic nerve activity. J Appl Physiol 92: 1539-1552, 2002.

12. Dow P. Estimations of cardiac output and central blood volume by dye dilution. Physiol Rev 36: 77-102, 1956.

13. Duncan A, Meek JH, Clemence M, Elwell CE, Tyszczuk L, Cope M, Delpy DT. Optical pathlength measurements on adult head, calf and forearm and the head of the newborn infant using phase resolved optical spectroscopy. Phys Med Biol 40: 295-304, 1995.

14. Emtner M, Porszasz J, Burns M, Somfay A, Casaburi R. Benefits of supplemental oxygen in exercise training in nonhypoxemic chronic obstructive pulmonary disease patients. Am J Respir Crit Care Med 168: 1034-1042, 2003.

15. Global Initiative for Chronic Obstructive Lung Disease. Global strategy for the diagnosis, management, and prevention of chronic obstructive pulmonary disease (Updated 2014): http://www.goldcopd.org/uploads/ users/files/GOLD_Report2014_Feb07.

16. Guenette JA, Vogiatzis I, Zakynthinos S, Athanasopoulos D, Koskolou M, Golemati S, Vasilopoulou M, Wagner HE, Roussos C, Wagner PD, Boushel R. Human respiratory muscle blood flow measured by near-infrared spectroscopy and indocyanine green. J Appl Physiol 104: 1202-1210, 2008.

17. Harms CA, Babcock MA, McClaran SR, Pegelow DF, Nickele GA, Nelson WB, Dempsey JA. Respiratory muscle work compromises leg blood flow during maximal exercise. J Appl Physiol 82: 1573-1583, 1997.

18. Harms CA, Thomas A, Wetter J, McClaran SR, Pegelow DF, Nickele GA, Nelson WB, Hanson P, Dempsey JA. Effects of respiratory muscle work on cardiac output and its distribution during maximal exercise. $J$ Appl Physiol 85: 609-618, 1998.

19. Hopkinson NS, Dayer MJ, Moxham J, Polkey MI. Abdominal muscle fatigue following exercise in chronic obstructive pulmonary disease. Respir Res 11: 15, 2010.

20. Kalliokoski KK, Scheede-Bergdahl C, Kjaer M, Boushel R. Muscle perfusion and metabolic heterogeneity: insights from non-invasive imaging techniques. Exerc Sport Sci Rev 34: 164-170, 2006.

21. Kyroussis D, Polkey MI, Hamnegard CH, Mills GH, Green M, Moxham J. Respiratory muscle activity in patients with COPD walking to exhaustion with and without pressure support. Eur Respir J 15: 649-655, 2000.

22. Kyroussis D, Polkey MI, Keilty SE, Mills GH, Hamnegard CH, Moxham J, Green M. Exhaustive exercise slows inspiratory muscle relaxation rate in chronic obstructive pulmonary disease. Am J Respir Crit Care Med 153: 787-793, 1996.

23. Laude EA, Duffy NC, Baveystock C, Dougill B, Campbell MJ, Lawson R, Jones PW, Calverley PM. The effect of heliox and oxygen on exercise performance in chronic obstructive pulmonary disease: a randomized crossover trial. Am J Respir Crit Care Med 173: 865-870, 2006.

24. Laveneziana P, Valli G, Onorati P, Paoletti P, Ferrazza AM, Palange P. Effect of heliox on heart rate kinetics and dynamic hyperinflation during high-intensity exercise in COPD. Eur J Appl Physiol 111: 225-234, 2011.

25. Lee DL, Lee H, Chang HW, Chang AY, Lin SL, Huang YC. Heliox improves hemodynamics in mechanically ventilated patients with chronic obstructive pulmonary disease with systolic pressure variations. Crit Care Med 33: 968-973, 2005.

26. Louvaris Z, Zakynthinos S, Aliverti A, Habazettl H, Vasilopoulou M, Andrianopoulos V, Wagner H, Wagner P, Vogiatzis I. Heliox increases quadriceps muscle oxygen delivery during exercise in COPD patients with and without dynamic hyperinflation. J Appl Physiol 113: 1012-1023, 2012.

27. Maltais F, Simon M, Jobin J, Desmeules M, Sullivan MJ, Bélanger M, Leblanc P. Effects of oxygen on lower limb blood flow and O2 uptake during exercise in COPD. Med Sci Sports Exerc 33: 916-922, 2001.

28. Miller MR, Hankinson J, Brusasco V, Burgos F, Casaburi R, Coates A, Crapo R, Enright P, van der Grinten CP, Gustafsson P, Jensen R, Johnson DC, MacIntyre N, McKay R, Navajas D, Pedersen OF, Pellegrino R, Viegi G, Wanger J. Standardisation of spirometry. Eur Respir J 26: 319-338, 2005.

29. Ninane V, Rypens F, Yernault JC, De Troyer A. Abdominal muscle use during breathing in patients with chronic airflow obstruction. Am Rev Respir Dis 146: 16-21, 1992.

30. O'Donnell DE, Bain DJ, Webb KA. Factors contributing to relief of exertional breathlessness during hyperoxia in chronic airflow limitation. Am J Respir Crit Care Med 155: 530-535, 1997.

31. O'Donnell DE, D'Arsigny C, Webb KA. Effects of hyperoxia on ventilatory limitation during exercise in advanced chronic obstructive pulmonary disease. Am J Respir Crit Care Med 163: 892-898, 2001.

32. Oelberg DA, Kacmarek M, Pappagianopoulos PP, Ginns LC, Systrom DM. Ventilatory and cardiovascular responses to inspired He-O2 during exercise in chronic obstructive pulmonary disease. Am J Respir Crit Care Med 179: 1876-1882, 1998. 
33. Palange P, Crimi E, Pellegrino R. Supplemental oxygen and heliox: 'new' tools for exercise training in chronic obstructive pulmonary disease. Curr Opin Pulm Med 11: 145-148, 2005.

34. Palange P, Valli G, Onorati P, Antonucci R, Paoletti P, Rosato A, Manfredi F, Serra P. Effect of Heliox on lung dynamic hyperinflation, dyspnoea, and exercise endurance capacity in COPD patients. $J$ Appl Physiol 85: 1637-1642, 2004.

35. Polkey MI, Kyroussis D, Hamnegard CH, Mills GH, Hughes PD, Green M, Moxham J. Diaphragm performance during maximal voluntary ventilation in chronic obstructive pulmonary disease. Am J Respir Crit Care Med 155: 642-648, 1997.

36. Polkey MI, Kyroussis D, Keilty SE, Hamnegard CH, Mills GH, Green M, Moxham J. Exhaustive treadmill exercise does not reduce twitch transdiaphragmatic pressure in patients with COPD. Am J Respir Crit Care Med 152: 959-964, 1995.

37. Richardson RS, Knight DR, Poole DC, Kurdak SS, Hogan MC, Grassi B, Wagner PD. Determinants of maximal exercise $\mathrm{VO}_{2}$ during single leg knee-extensor exercise in humans. Am J Physiol 268: 1453-1461, 1995.

38. Sapirstein LA. Fractionation of the cardiac output of rats with isotopic potassium. Circ Res 1956: 4, 689-692.

39. Simon M, LeBlanc P, Jobin J, Desmeules M, Sullivan MJ, Maltais F. Limitation of lower limb $\mathrm{VO}(2)$ during cycling exercise in COPD patients. J Appl Physiol 90: 1013-1019, 2001

40. Somfay A, Porszasz J, Lee SM, Casaburi R. Dose-response effect of oxygen on hyperinflation and exercise endurance in non hypoxaemic COPD patients. Eur Respir J 18: 77-84, 2001.

41. Stein DA, Bradley BL, Miller W. Mechanisms of oxygen effects on exercise in chronic obstructive pulmonary disease. Chest 81: 6-10, 1982.
42. Swallow EB, Reyes D, Hopkinson NS, Man WD, Porcher R, Cetti EJ, Moore AJ, Moxham J, Polkey MI. Quadriceps strength predicts mortality in patients with moderate to severe chronic obstructive pulmonary disease. Thorax 62: 115-120, 2007.

43. van der Zee P, Cope M, Arridge SR, Essenpreis M, Potter LA, Edwards AD, Wyatt JS, McCormick DC, Roth SC, Reynolds EO. Experimentally measured optical pathlengths for the adult head, calf and forearm and the head of the newborn infant as a function of inter optode spacing. Adv Exp Med Biol 316: 143-153, 1992.

44. Vogiatzis I, Athanasopoulos D, Boushel R, Guenette JA, Koskolou M, Vasilopoulou M, Wagner H, Roussos C, Wagner PD, Zakynthinos S. Contribution of respiratory muscle blood flow to exercise-induced diaphragmatic fatigue in trained cyclists. $J$ Physiol 586: 5575-5587, 2008.

45. Vogiatzis I, Athanasopoulos D, Habazettl H, Aliverti A, Louvaris Z, Cherouveim E, Wagner H, Roussos C, Wagner PD, Zakynthinos S. Intercostal muscle blood flow limitation during exercise in chronic obstructive pulmonary disease. Am J Respir Crit Care Med 182: 1105-1113, 2010.

46. Vogiatzis I, Habazettl H, Aliverti A, Athanasopoulos D, Louvaris Z, Lo Mauro A, Wagner H, Roussos C, Wagner PD, Zakynthinos S. Effect of helium breathing on intercostals and quadriceps muscle blood flow during exercise in COPD patients. Am J Physiol Regul Integr Comp Physiol 300: R1549-R1559, 2011.

47. Vogiatzis I, Zakynthinos S. Factors limiting exercise tolerance in chronic lung diseases. Comp Physiol 2: 1779-1817, 2012.

48. Vogiatzis I, Louvaris Z, Habazettl H, Andrianopoulos V, Wagner H, Roussos C, Wagner PD, Zakynthinos S. Cerebral cortex oxygen delivery and exercise limitation in patients with COPD. Eur Respir J 41: 295-301, 2013 